\title{
Antibody against Helicobacter pylori CagA and VacA and the risk for gastric cancer
}

\author{
Y Yamaoka, T Kodama, K Kashima, D Y Graham
}

\begin{abstract}
Aim-Helicobacter pylori is associated with gastric cancer. Our aim was to investigate whether CagA or VacA seropositivity provides additional risk for gastric cancer.

Methods-Sera from 110 gastric cancer patients were sex and aged matched with asymptomatic controls. $H$ pylori status was determined by IgG enzyme immunoassay (HM-CAP EIA); CagA status was assessed by enzyme linked immunosorbent assay (ELISA) (OraVax) and immunoblotting (Chiron), and VacA status by immunoblotting using recombinant proteins as antigens.

Results-H pylori infection was associated with an increased risk of gastric cancer (odds ratio $(\mathrm{OR})=2.19,95 \%$ confidence interval 1.17 to 4.1 ). Subgroup analysis showed a significant association with intestinal type $(O R=2.94,1.35$ to $6.41)$, distal type $(O R=2.97,1.39$ to 6.33$)$, early gastric cancer $(O R=3.74,1.54$ to 9.06), and age $\leqslant 55$ years $(O R=8.33,2.04$ to 34.08$)$, but not with diffuse type $(\mathrm{OR}=$ $0.83)$, proximal type $(O R=1.0)$, advanced gastric cancer $(O R=1.13)$, or age $>55$ years $(O R=1.40)$. Serum CagA IgG and VacA antibody positivity was present in similar proportions in patients with and without cancer, with no significant differences in histological classification, clinical stage, or location $(p>0.3)$.

Conclusions-H pylori infection causes chronic gastritis and is associated with the development of gastric cancer. Neither CagA nor VacA seropositivity added additional information or stratification. (F Clin Pathol 1999;52:215-218)
\end{abstract}

Department of

Medicine, Veterans

Affairs Medical Center

(111D), 2002 Holcombe

Blvd, Houston, Texas

77030, USA

Y Yamaoka

D Y Graham

Third Department of Internal Medicine,

Kyoto Prefectural

University of

Medicine, Kyoto, Japan

T Kodama

K Kashima

Correspondence to: Dr Yamaoka.

email: yoshio@wt.net

Accepted for publication 27 November 1998

Keywords: Helicobacter pylori; CagA gene; VacA gene; gastric cancer; virulence factors

Helicobacter pylori infection is now accepted as the major cause of chronic gastritis. Several epidemiological studies have shown that $H p y$ lori infection is also linked to the gastritis associated diseases (gastric cancer and peptic ulcer). ${ }^{1-3}$ In 1994, the International Agency for Research on Cancer categorised $H$ pylori infection as a group I carcinogen. ${ }^{4}$ In 1993, an estimated $0.4 \%$ of the 60 million Japanese who were infected with $H$ pylori were diagnosed with gastric cancer. ${ }^{56}$ Thus although gastric cancer is one of the commonest cancers in Japan, only a small percentage of individuals with $H$ pylori infection ever develop it. One possible reason for differences in outcome of
$H$ pylori infection may relate to differences in virulence of $H$ pylori strains.

Studies on bacterial virulence have focused primarily on two groups of putative bacterial virulence factors, the cag pathogenicity island (for which CagA antibody is a marker) and the vacuolating cytotoxin, VacA. Recent serological studies have shown that the CagA and VacA seropositivity were associated with an increased risk of developing atrophic gastritis and gastric cancer. $^{7-11}$

In Japan, the predominant types of $H$ pylori circulating in the population express CagA and VacA. ${ }^{12-17}$ Two recent reports regarding the possible relation of serum anti-CagA antibody in gastric cancer in Japan reached opposite conclusions. $^{1819}$ Katagiri et al reported that there was no relationship between CagA seropositivity and gastric cancer, ${ }^{18}$ whereas Shimoyama et al reported the opposite. ${ }^{19}$ Both studies used recombinant CagA protein as the antigen for the serological study but the source and structure differed. Katagiri et al used orv220, a 65000 fragment CagA protein from OraVax Inc (Cambridge, Massachusetts, USA) whereas Shimoyama et al used a 25500 fragment antigen from Immunobiological Research Institute Siena (IRIS, Siena, Italy). It is not clear whether their discrepant findings resulted from the use of different populations or different methods, or from differences in the antigens used to detect anti-CagA antibodies.

We used both CagA antigens to investigate whether CagA seropositivity was associated with increasing risk of gastric cancer in Japan. We also examined the relation between the VacA seropositivity and gastric cancer using a recombinant VacA antigen.

\section{Methods}

PATIENTS

Sera were obtained from 110 Japanese patients with histologically proven gastric cancer (80 men and 30 women, mean age 64.5 years, age range 42 to 84 ). Early gastric cancer was diagnosed pathologically by the growth of a tumour confined to the mucosa and submucosa of the stomach, as defined by the Japanese Research Society for Gastric Cancer. ${ }^{20}$ The histological type of the malignancy was determined according to Lauren, as either intestinal or diffuse type. $^{21}$

Two control groups were evaluated. First, each cancer patient was sex and aged matched with asymptomatic control (one control for each case) to assess the role of $H$ pylori infection in gastric cancer (control 1). A second control (control 2) compared CagA antibody and VacA antibody status in $H$ pylori positive 
cases and required the addition of $29 \mathrm{H}$ pylori antibody positive age and sex matched cases. None of the controls had histology of peptic ulcer disease or dyspepsia. None of the patients had been treated for $H$ pylori, had received recent blood transfusions, non-steroidal antiinflammatory drugs, proton pump inhibitors, or antibiotics within the previous three months.

Informed consent was obtained from all patients and the protocol was approved by the Hospital ethics committee.

Serum samples were stored at $-80^{\circ} \mathrm{C}$ until serological testing.

ENZYME IMMUNOASSAY FOR H PYLORI

$H$ pylori status was determined by IgG antibodies to $H$ pylori using a commercially available enzyme immunoassay (EIA) kit (HM-CAP EIA, Enteric Products Inc). This assay system is reported to have $98.7 \%$ sensitivity and $100 \%$ specificity in the United States ${ }^{22}$ and $100 \%$ sensitivity and $96 \%$ specificity in Japan in comparison with the urea breath test. ${ }^{23}$ A cutoff optical density of 0.30 was chosen, according to Asaka et al. ${ }^{23}$ Furthermore, a sensitivity and specificity of $96 \%$ and $98 \%$ have been found in 100 dyspeptic patients as determined by culture and histological analysis in our laboratory (data not shown). High titre antibody was defined by an optical density greater than 1.00.

ENZYME IMMUNOASSAY FOR CagA USING RECOMBINANT CagA ANTIGEN

Microtitre wells were coated with $1 \mu \mathrm{g} /$ well orv220 antigen fragment of CagA (OraVax enzyme linked immunosorbent assay (ELISA), OraVax Inc) in $100 \mu \mathrm{l} /$ well carbonatebicarbonate buffer (100 mM, pH 9.6), overnight at $4^{\circ} \mathrm{C}$. After washing and blocking with $200 \mu \mathrm{l} /$ well $2.5 \%$ non-fat dried milk (NFDM) in phosphate buffered saline (PBS)-Tween (one hour, $37^{\circ} \mathrm{C}$ ), serum samples diluted 1 in 100 in $100 \mu \mathrm{l} /$ well NFDM/PBS-Tween were incubated at $37^{\circ} \mathrm{C}$ for one hour.

The second antibody, a goat antihuman IgG alkaline phosphatase conjugate, was then added at a dilution of $1: 1000$ at $37^{\circ} \mathrm{C}$ for one hour. After incubation with alkaline phosphatase substrate solution at $1 \mu \mathrm{g} / \mathrm{ml}$ in diethylamine- $\mathrm{MgCl}_{2}$ buffer at room temperature for 20 minutes, the optical density was read at $405 \mathrm{~nm}$. A standard curve of high titre positive and control serum samples was included on each plate. Results were expressed in ELISA units $(0-100)$ determined from the standard curve. The cutoff was determined as 5.0 ELISA units. It was calculated as the mean plus 3 SD of the results obtained from 30 patients negative for $H$ pylori (culture, histology, and urea breath test negative).

IMMUNOBLOTTING ASSAY FOR CagA AND VacA Chiron recombinant immunoblot $H$ pylori immunoassay (Chiron-RIBA, Chiron Corporation, Emeryville, California, USA) consisted of two different strips; one with a $H$ pylori lysate (membrane derived antigens) and the other with the pathogenicity markers of this bacterium including VacA, CagA, and urease.

Membrane strips were incubated with 1:50 dilution of sera on a shaker for 4 to 4.5 hours at room temperature. After incubation, unbound serum components were removed by washing and aspiration. After washing, peroxidase labelled goat antihuman IgG conjugate was added to each strip and incubated for 9 to 11 minutes at room temperature. Substrate solution (hydrogen peroxide and 4-choro-1naphthol) was added to each strip and agitated for 15 to 20 minutes at room temperature, after which the strips were washed twice with deionised water, dried, and mounted on nonabsorbent paper. Serum positive and negative controls were included with each assay. Two levels of human IgG (level I, low control; level II, high control) were included on each strip as internal controls. H pylori reactivity was determined by comparing the intensity of the human IgG (level I and level II) internal control bands on each strip. The identity of the antigen bands was scored in relation to the intensities of the internal IgG controls as follows: score -, intensity of band is absent; \pm , less than intensity of the level I IgG control band; 1+, equal to intensity of the level I IgG control band; $2+$, greater than intensity of the level I IgG control band and less than intensity of the level II IgG control band; 3+, equal to intensity of the level II IgG control band; $4+$, greater than intensity of the level II IgG control band.

A cutoff for seropositivity was defined as comparing + and \pm data obtained from 30 $H$ pylori negative controls. As a result, \pm data are regarded as positive for CagA antibody and negative for $H$ pylori status and anti-VacA antibody.

Results are given as odds ratios (OR) and 95\% confidence intervals (CI).

\section{Results}

Seventy three patients had early gastric cancer and 37 had advanced gastric cancer.

Histologically, 88 patients had intestinal type adenocarcinoma and 22 had diffuse type cancer. Eighty seven gastric cancers had distal type (antrum to body) and 23 had proximal type (cardia and fundus).

\section{H PYLORI AND GASTRIC CANCER}

$H$ pylori infection was associated with an increased risk of gastric cancer $(\mathrm{OR}=2.19$, $95 \%$ CI 1.17 to 4.1 ; table 1$)$. Subgroup analysis showed a significant association with intestinal type $(\mathrm{OR}=2.94,95 \%$ CI 1.35 to $6.41)$, distal type $(\mathrm{OR}=2.97,95 \%$ CI 1.39 to 6.33), early gastric cancer $(\mathrm{OR}=3.74,95 \% \mathrm{CI}$ 1.54 to 9.06$)$, and age $(\leqslant 55$ years) $(\mathrm{OR}=$ $8.33,95 \%$ CI 2.04 to 34.08 ), but not with diffuse type $(\mathrm{OR}=0.83)$, proximal type $(\mathrm{OR}=$ $1.0)$, advanced gastric cancer $(\mathrm{OR}=1.13)$, or age $>55$ years $(\mathrm{OR}=1.40)($ table 1$)$. The majority of patients with distal type early gastric cancer (57 of 60 patients; $95 \%$ ) were $H$ pylori antibody positive (OR $=8.14,95 \% \mathrm{CI}$ 2.25 to 29.46 ).

Sixty per cent (39 of 65) H pylori positive patients with early gastric cancer had high titre of $H$ pylori antibody (OR $=2.11,95 \%$ CI 1.05 to 4.25), compared with only eight of 25 patients (32\%) with advanced gastric cancer 
Table 1 Relation between gastric cancer and seropositivity of anti-H pylori IgG antibody

\begin{tabular}{|c|c|c|c|c|c|c|}
\hline & \multirow[b]{2}{*}{ No } & \multicolumn{2}{|c|}{$\begin{array}{l}\text { Proportion of } \\
\text { positive results (\%) }\end{array}$} & \multirow[b]{2}{*}{ Odds ratio } & \multirow[b]{2}{*}{$95 \% C I$} & \multirow[b]{2}{*}{$p$ Value } \\
\hline & & Case & Control & & & \\
\hline All patients & 110 & 81.8 & 67.3 & 2.19 & 1.17 to 4.10 & $<0.01$ \\
\hline Distal type & 87 & 86.2 & 67.8 & 2.97 & 1.39 to 6.33 & 0.01 \\
\hline Proximal type & 23 & 65.2 & 65.2 & 1.00 & 0.29 to 3.36 & NS \\
\hline Intestinal type & 89 & 87.5 & 70.5 & 2.94 & 1.35 to 6.41 & 0.01 \\
\hline Diffuse type & 22 & 59.1 & 63.6 & 0.83 & 0.24 to 2.78 & NS \\
\hline Early stage & 73 & 89.0 & 68.5 & 3.74 & 1.54 to 9.06 & 0.005 \\
\hline Advanced & 37 & 67.6 & 64.9 & 1.13 & 1.54 to 9.06 & NS \\
\hline Age $\leqslant 55$ years & 28 & 89.3 & 50.0 & 8.33 & 2.04 to 34.08 & 0.005 \\
\hline Age $>55$ years & 82 & 79.3 & 75.6 & 1.40 & 0.68 to 2.89 & NS \\
\hline
\end{tabular}

CI, confidence interval.

Table 2 Relation between gastric cancer and seropositivity of anti-CagA antibody (OraVax)

\begin{tabular}{lllllll}
\hline \multicolumn{5}{c}{$\begin{array}{l}\text { Proportion of } \\
\text { positive results (\%) }\end{array}$} & & \\
\cline { 3 - 4 } & No & Case & Control & Odds ratio & $95 \%$ CI & p Value \\
\hline All patients & 90 & 83.3 & 81.1 & 1.16 & 0.54 to 2.50 & NS \\
Distal type & 75 & 84.0 & 81.3 & 1.20 & 0.52 to 2.81 & NS \\
Proximal type & 15 & 80.0 & 80.0 & 1.00 & 0.17 to 5.99 & NS \\
Intestinal type & 77 & 83.1 & 79.2 & 1.29 & 0.57 to 2.91 & NS \\
Diffuse type & 13 & 84.6 & 92.3 & 0.45 & 0.04 to 5.79 & NS \\
Early stage & 65 & 87.7 & 80.0 & 1.78 & 0.68 to 4.64 & NS \\
Advanced & 25 & 72.0 & 84.0 & 0.49 & 0.12 to 1.95 & NS \\
Age $\leqslant 55$ years & 25 & 84.0 & 76.0 & 1.66 & 0.41 to 6.79 & NS \\
Age $>$ 55 years & 65 & 83.1 & 83.1 & 1.00 & 0.40 to 2.50 & NS \\
\hline
\end{tabular}

$\mathrm{CI}$, confidence interval.

Table 3 Relation between gastric cancer and seropositivity of anti-CagA antibody (Chiron)

\begin{tabular}{|c|c|c|c|c|c|c|}
\hline & \multirow[b]{2}{*}{ No } & \multicolumn{2}{|c|}{$\begin{array}{l}\text { Proportion of } \\
\text { positive results (\%) }\end{array}$} & \multirow[b]{2}{*}{ Odds ratio } & \multirow[b]{2}{*}{$95 \% C I$} & \multirow[b]{2}{*}{$p$ Valu } \\
\hline & & Case & Control & & & \\
\hline All patients & 90 & 73.3 & 71.1 & 1.12 & 0.58 to 2.15 & NS \\
\hline Distal type & 75 & 74.7 & 72.0 & 1.15 & 0.55 to 2.37 & NS \\
\hline Proximal type & 15 & 66.7 & 66.7 & 1.00 & 0.22 to 4.57 & NS \\
\hline Intestinal type & 77 & 74.0 & 74.0 & 1.00 & 0.49 to 2.07 & NS \\
\hline Diffuse type & 13 & 69.2 & 61.5 & 1.41 & 0.28 to 7.13 & NS \\
\hline Early stage & 65 & 81.5 & 72.3 & 1.69 & 0.74 to 3.88 & NS \\
\hline Advanced & 25 & 52.0 & 68.0 & 0.51 & 0.16 to 1.61 & NS \\
\hline Age $\leqslant 55$ years & 25 & 84.0 & 80.0 & 1.31 & 0.31 to 5.60 & NS \\
\hline Age $>55$ years & 65 & 69.2 & 67.8 & 1.07 & 0.51 to 2.26 & NS \\
\hline
\end{tabular}

CI, confidence interval.

Table 4 Relation between gastric cancer and seropositivity of anti-VacA antibody (Chiron)

\begin{tabular}{lllllll}
\hline \multicolumn{5}{c}{$\begin{array}{l}\text { Proportion of } \\
\text { positive results (\%) }\end{array}$} & & \\
\cline { 3 - 4 } & No & Case & Control & Odds ratio & $95 \%$ CI & p Value \\
\hline All patients & 90 & 82.2 & 81.1 & 1.08 & 0.51 to 2.29 & NS \\
Distal type & 75 & 80.0 & 81.3 & 0.92 & 0.41 to 2.07 & NS \\
Proximal type & 15 & 93.3 & 80.3 & 3.50 & 0.32 to 38.26 & NS \\
Intestinal type & 77 & 82.8 & 83.1 & 0.91 & 0.40 to 2.10 & NS \\
Diffuse type & 13 & 84.6 & 69.2 & 2.44 & 0.36 to 16.56 & NS \\
Early stage & 65 & 84.6 & 81.5 & 1.25 & 0.50 to 3.13 & NS \\
Advanced & 25 & 76.0 & 80.0 & 0.79 & 0.21 to 3.03 & NS \\
Age $\leqslant 55$ years & 25 & 92.0 & 88.0 & 1.57 & 0.24 to 10.31 & NS \\
Age $>$ 55 years & 65 & 78.5 & 78.5 & 1.00 & 0.43 to 2.31 & NS \\
\hline
\end{tabular}

CI, confidence interval.

(early gastric cancer $v$ advanced gastric cancer, $\mathrm{p}=0.031)$.

VIRULENCE FACTORS AND GASTRIC CANCER

The presence of IgG antibody to CagA was similar in gastric cancer and control subjects using both the OraVax ELISA and the Chiron RIBA $(83.3 \%$ \% $81.1 \%$ with OraVax ELISA, $73.3 \%$ v $71.1 \%$ with Chiron immunoblots, for gastric cancer $v$ H pylori positive controls, respectively) ( $p>0.9$; tables 2 and 3 ). The results were concordant in $86 \%$ (both positive or both negative in 64 and 13, respectively, among the cancer cases). The results with the two CagA antibody tests were discordant in $14 \%$, with the OraVax ELISA yielding the higher estimate (OraVax+/Chiron- in 11 and OraVax-/Chiron+ in two). Nevertheless, the conclusions of the study were unchanged, irrespective of which CagA antigen was used.

VacA IgG antibody was positive in $82.2 \%$ of gastric cancers and $81.1 \%$ of controls (table 4 ). There were no significant differences in histological classification, clinical stage, or location of the tumour and CagA or VacA status.

\section{Discussion}

This study confirmed that $H$ pylori infection is associated with an increased risk of gastric cancer. ${ }^{24-27}$ We found a significant association between $H$ pylori infection and intestinal type, distal type, early gastric cancer, and age $\leqslant 55$ years. $H$ pylori infection is expected to have a strong relation to intestinal type gastric cancer, as chronic atrophic gastritis was recognised as a risk factor for gastric cancer for decades before the identification of $H$ pylori as a cause of gastritis. ${ }^{28}{ }^{29}$ It is currently thought that $H$ pylori infection has an indirect relation to gastric cancer and is largely responsible for the development of atrophic gastritis and the precursor lesion, intestinal metaplasia. ${ }^{30}$ In Japan, the prevalence of atrophic gastritis is extremely high, with a $90 \%$ incidence in people over 60 years age. ${ }^{31}$

There are only a few studies of the relation between $H$ pylori and both early gastric cancer and advanced gastric cancer. ${ }^{24} 2632$ Our results are in agreement with those of Asaka et $a l^{24}$ who reported that $H$ pylori $\operatorname{IgG}$ antibody titres were significantly higher in early cancer than in advanced cancer. The lower frequency of high titre IgG antibody in advanced cancer may be the result of a decrease in antibody titre, because of the increasing extent of intestinal metaplasia associated with transition from the intestinal type of early gastric cancer to advanced cancer, such that the local environment is no longer ideal for growth of H pylori. ${ }^{24} 334$

There are many reports using recombinant CagA proteins used in this study, ${ }^{9} 10181935$ but no studies comparing them. This study suggests that numerical results from studies using different antigens and different protocols may not be comparable. Epidemiology studies by Blaser et $a l^{9}$ and Parsonnet et $a l^{10}$ used the OraVax antigen, whereas the Eurogast Study Group $^{35}$ used IRIS antigen, which is also used in the Chiron test. It is not clear which, or if either, antigen provides the better assessment of the prevalence of infection with $H$ pylori that contain the cag pathogenicity island. Overall, the conclusions of this study were the same (that is, that there was no relation between CagA antibody status and gastric cancer), irrespective of which antigen was used. Nevertheless, the proportion with positive tests differed, with the OraVax ELISA yielding the higher estimate. The reason for the difference is unclear. It is possible that the ELISA may detect conformational and linear epitopes whereas the immunoblot is likely to detect only 
linear epitopes. Whatever the cause, even the OraVax test - which provided the highest rate of anti-CagA antibody-yielded a lower frequency in Japanese patients than evaluation of CagA status by polymerase chain reaction or immunoblotting of $\mathrm{H}$ pylori isolates obtained from patients with different $H$ pylori associated diseases, ${ }^{12-17}$ suggesting that data derived using this test may not accurately reflect the true prevalence of CagA positive $H$ pylori in a population. To obtain reliable data it would appear prudent for investigators interested in the true prevalence of CagA or VacA positive $H$ pylori in a disease or region to validate the assays in their geographical region.

Several other variables can influence the outcome of studies evaluating the possible role of putative virulence factors in various $H$ pylori related diseases. For example, different proportions of different histological types (such as advanced type $v$ early type) could easily lead to different outcomes, and such unrecognised differences may be responsible for the different results obtained by the studies of Katagiri et al and Shimoyama et al. ${ }^{18}{ }^{19}$ It appears unlikely that differences in the test used were responsible for the difference in results they obtained.

Rudi et al reported that VacA antibody was associated with an increased risk of gastric cancer $(\mathrm{OR}=1.74,95 \% \mathrm{CI} 1.08$ to 2.78$) .{ }^{11}$ However, there was no relation between the VacA and gastric cancer in this study. The two studies used different procedures and evaluated patients from different countries. Whether the differences are procedural or geographical will require additional investigation.

We acknowledge the support of Chiron Corporation for providing us with the Chiron RIBA $H$ pylori SIA kit. We also acknowledge the support of OraVax Inc for providing us with the recombinant CagA antigen (orv220). We thank Toshiharu University of Medicine), Hayazo Kubo and Hisakazu Yamagishi (Second Department of Surgery, Kyoto Prefectural University of Medicine), Eiji Naito, Takashi Kohso, and Yoshihide Tatsumi of Medicine), Eiji Naito, Takashi Kohso, and Yoshihide Tatsumi University of Medicine) for assisting in the collection of sera.

1 Forman D, Newell DG, Fullerton F, et al. Association between infection with Helicobacter pylori and risk of gas-
tric cancer: evidence from a prospective investigation. BMF 1991;302:1302-5.

2 Nomura A, Stemmermann GN, Chyou PH, et al. Helicobacter pylori infection and gastric carcinoma among Japanese Americans in Hawaii. N Engl F Med 1991;325:1132-6.

3 Parsonnet J, Friedman GD, Vandersteen DP, et al. Helicobacter pylori infection and the risk of gastric carcinoma. N Engl F Med 1991;325:1132-6.

4 International Agency for Research on Cancer. Schistosomes, liver flukes and Helicobacter pylori. IARC monographs on the evaluation of carcinogenic risks to humans, vol 61. Lyon: IARC, 1994:177-240.

5 Japanese Ministry of Health and Welfare. Malignant neoplasm of stomach: databook in disease-related total numbers of the patients in Japan. Tokyo: Ministry of Health and Welfare, 1995:33.

6 Asaka M, Takeda H, Sugiyama T, et al. What roles does Helicobacter pylori play in gastric cancer? Gastroenterology 1997;113:S56-60.

7 Kuipers EJ, Perez-Perez GI, Meuwissen SGM, et al. HelicoKuipers EJ, Perez-Perez GI, Meuwissen SGM, et al. Helico-
bacter pylori and atrophic gastritis: importance of the CagA status. F Natl Cancer Inst 1995;87:1777-80.

8 Beales ILP, Crabtree JE, Scunes D, et al. Antibodies to cagA protein are associated with gastric atrophy in Helicobacter pylori infection. Eur $\mathcal{F}$ Gastroenterol Hepatol 1996;8:645-9.
9 Blaser MJ, Perez-Perez GI, Kleanthous H, et al. Infection with Helicobacter pylori strains possessing CagA is associated with an increased risk of developing adenocarcinoma of the stomach. Cancer Res 1995;55:2111-15.

10 Parsonnet J, Friedman GD, Orentreich N, et al. Risk for gastric cancer in people with CagA positive or CagA negative Helicobacter pylori infection. Gut 1997;40:297-301.

11 Rudi J, Kolb C, Maiwald M, et al. Serum antibodies against the Helicobacter pylori proteins CagA and VacA are associated with an increased risk for gastric adenocarcinoma. Dig Dis Sci 1997;42:1652-9.

12 Shimoyama T, Fukuda S, Tanaka M, et al. High prevalence of the CagA-positive Helicobacter pylori strains in Japanese asymptomatic patients and gastric cancer patients. Scand $\mathcal{F}$ Gastroenterol 1997;32:465-8.

13 Maeda S, Ogura K, Yoshida $\mathrm{H}$, et al. Major virulence factors, VacA and CagA, are commonly positive in Helico-

14 Ito Y, Azuma T, Ito S, et al. Analysis and typing of the vacA gene from CagA-positive strains of Helicobacter pylori isolated in Japan. F Clin Microbiol 1997;35:1710-14

15 Yamaoka Y, Kita M, Kodama T, et al. Induction of various cytokines and development of severe mucosal inflammation by CagA gene-positive Helicobacter pylori strains. Gut 1997;41:442-51.

16 Yamaoka Y, Kita M, Kodama T, et al. Chemokines in the gastric mucosa in Helicobacter pylori infection. Gut 1998; 42:609-17.

17 Yamaoka Y, Kodama T, Graham DY, et al. Search for putative virulence factors of Helicobacter pylori: the low molecular weight (33-35K) antigen. Dig Dis Sci 1998;43: 1482-1487.

18 Katagiri M, Takeda H, Kudo M, et al. Infection with CagA+ $\mathrm{H}$. pylori strains is not associated with gastric cancer in Japan [abstract]. Gastroenterology 1997;112(suppl):A589.

19 Shimoyama T, Mikami T, Fukuda S, et al. CagA seropositivity associates with development of gastric cancer in a Japanese population: a case control study [abstract]. Gastroenterology 19;112(suppl):A655.

20 Japanese Research Society for Gastric Cancer. Part 1. Clinical, surgical, and conclusive findings. In: Nishi M, Omori Y, Miwa D, eds. Fapanese classification of gastric carcinoma, 1 st English edition. Tokyo: Kenehara and Co, 1995:1-351.

21 Lauren P. The two histological main types of gastric carcinomas: diffuse and so-called intestinal type of carcinoma. Acta Pathol Microbiol Scand 1965;64:31-49.

22 Evans DJ, Evans DG, Graham DY, et al. A sensitive and specific serologic test for detection of Campylobacter pylori infection Gastroenterology 1989:96:1004-8.

23 Asaka M, Kimura T, Kudo M, et al. Relationship of Helicobacter pylori to serum pepsinogens in an asymptomatic Japanese population. Gastroenterology 1992;102:760-6.

24 Asaka M, Kimura T, Kato M, et al. Possible role of Helicobacter pylori infection in early gastric cancer development. Cancer 1994;73:2691-4.

25 Fukuda H, Saito D, Hayashi S, et al. Helicobacter pylori infection, serum pepsinogen level and gastric cancer: a case-control study in Japan. fpn f Cancer Res 1995;86:6471 .

26 Kikuchi S, Wada O, Nakajima T, et al. Serum antiHelicobacter pylori antibody and gastric carcinoma among young adults. Cancer 1995;75:2789-93.

27 Huang JQ, Sridhar S, Chen Y, et al. Meta-analysis of the relationship between Helicobacter pylori and gastric cancer. Gastroenterology 1998;114:1169-79.

28 Correa P, Haenszel W, Cuello C, et al. A model for gastric cancer epidemiology. Lancet 1975; ii:58-60.

29 Taki K, Kuwabara N. Studies on histogenesis of the gastric carcinoma using minute cancers. Pathol Res Pract 1981;172: $176-90$.

30 Graham DY. Helicobacter pylori infection in the pathogenesis of duodenal ulcer and gastric cancer: a model. Gastroenterology 1997;113:1983-91.

31 Kimura K, Satoh K, Yoshida Y, et al. Chronological extension of atrophic gastritis and intestinal metaplasia in normal Japanese. Eur f Gastroenterol Hepatol 1993;5(suppl 1):S85-91.

32 Estevens J, Fidalgo P, Tenderio T, et al. Anti-Helicobacter pylori antibodies prevalence and gastric adenocarcinoma in Portugal: report of a case-control study. Eur $\mathcal{F}$ Cancer Prevent $1993 ; 2: 377-80$

33 Karnes WE, Samloff IM, Siurala M, et al. Positive serum antibody and negative tissue staining for Helicobacter pylori in subjects with atrophic body gastritis. Gastroenterology 1991;101:167-74.

34 Craanen ME, Dekker W, Blok P, et al. Intestinal metaplasia and Helicobacter pylori: an endoscopic bioptic study of the gastric antrum. Gut 1992;33:16-20.

35 Webb PM, Forman D, Newell D, et al, and the Eurogast Study Group. An international association between prevalence of infection with CagA positive strains of $\mathrm{H}$ pylori and mortality from gastric cancer [abstract]. Gut 1997; 39(suppl 2):A1. 